\title{
Unexpected vertical wind speed profiles in the boundary layer over the southern North Sea
}

\author{
Anthony J. Kettle \\ Geophysical Institute, University of Bergen, P.O. Box 7803, Bergen 5020, Norway
}

\section{A R T I C L E I N F O}

\section{Article history:}

Received 4 May 2014

Received in revised form

18 July 2014

Accepted 25 July 2014

Available online 22 August 2014

Keywords:

Decoupled layers

FINO1

Internal boundary layer

Meteorological mast

North Sea

\begin{abstract}
A B S T R A C T
Shallow atmospheric internal boundary layers over the southern part of the North Sea are common. Analysis of one year of meteorological data from the FINO1 research platform in the German Bight reveals that vertical wind speed profiles frequently do not conform to the expected modified logarithmic profile of Monin-Obukhov similarity theory. The wind profiles are mostly characterized by local maxima or kinks within the first $100 \mathrm{~m}$ over the sea surface. The data reveals the most frequent occurrence of a single maximum, but multiple maxima are often present, and there are sometimes even reversed profiles with the wind speed decreasing with height. The expected modified logarithmic profile occurs for a minority of cases. The evidence suggests the frequent presence of internal boundary layers that propagate from coastal land masses that surround the North Sea. A census of vertical wind speed profiles is presented that shows how different inflection states are linked with wind speed and atmospheric stability. The kinks are most prevalent in the upper part of the measurement range near the $100 \mathrm{~m}$ hub height of modern offshore the wind turbines, so that internal boundary layers represent a possible concern for the offshore wind energy industry in the North Sea region.
\end{abstract}

(c) 2014 Elsevier Ltd. All rights reserved.

\section{Introduction}

The development of offshore wind energy projects over the last 20 years has intensified research into the structure and dynamics in the lowest $200 \mathrm{~m}$ over the sea surface where wind turbines currently operate. In predicting the wind energy potential at a given location, the wind industry typically makes a wind resource calculation at hub height by extrapolating near surface wind speed data (Sempreviva et al., 2008). The extrapolation is performed according to a power-law relationship or a modified logarithmic wind profile within the framework of Monin-Obukhov (MO) similarity theory. MO theory offers an integrated description of property profiles and turbulent fluxes of heat and momentum within the surface layer of the atmosphere (Arya, 2001). It has been applied to meteorological data collected from voluntary observing ships to estimate vertical profiles of air temperature, humidity and wind speed over the ocean. The MO approach has been an important interpretation tool to understand atmospheric profiles over the ocean. It has been expanded and modified to accommodate geophysical phenomena that affect the flux of mass and heat between the

E-mail address: ake043@gfi.uib.no ocean and atmosphere: surface waves, cool skin and diurnal warming effects, precipitation, and anomalous fluxes during low winds (Fairall et al., 1996, 2003). Mostly, these modifications have been developed and tested within the framework of scientific field studies within the lowest tens of meters of the atmosphere at fairly low wind speeds, and this has been used for accurate parameterizations of heat and momentum flux for the larger scale models (Fairall et al., 1996).

The development of offshore wind energy has led to the construction of high offshore meteorological masts at many offshore locations in order to more accurately assess the wind resource (Barthelmie et al., 2005; Sempreviva et al., 2008). Fig. 1 shows the location of offshore (and some onshore) high meteorological masts that have been used to investigate the marine atmospheric boundary layer (MABL) in coastal regions in northwest Europe. Many of the masts have been constructed to support the current and prospective wind farms in the North and Baltic Seas, highlighting the economic importance of this activity which is projected to continue (Breton and Moe, 2009; Bilgili et al., 2011; Sun et al., 2012; Nunalee and Basu, 2012). The offshore meteorological masts are typically well-instrumented with arrays of cup anemometers and air temperature sensors, and they often also have sonic anemometers and associated oceanographic instruments (see Neumann et al., 2004; Barthelmie et al., 2005; 


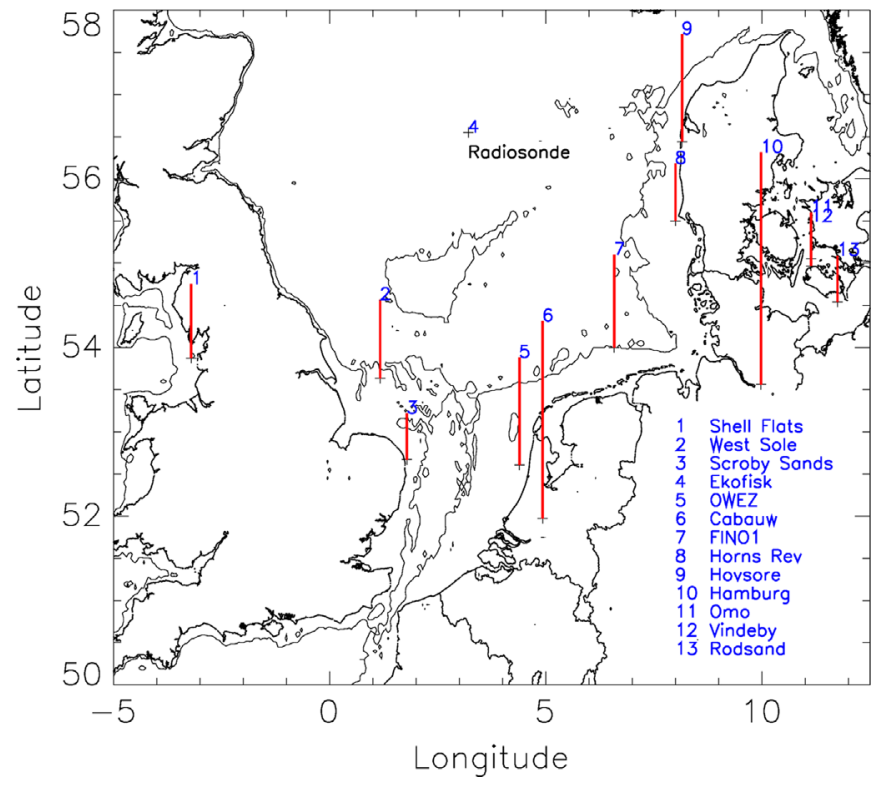

Fig. 1. Location of FINO1 in the southern North Sea with other high meteorological masts and installations in northwest Europe that are referenced in this article: Shell Flats (80 m; Argyle and Watson, 2012), West Sole (85 m; Wills, 1992), Scroby Sands (50 m; Argyle and Watson, 2012), Ekofisk (Beran et al., 2005), OWEZ (116 m; Sathe et al., 2011), Cabauw (213 m; Gryning et al., 2007), FINO1 (100 m; Neumann et al., 2003, 2004), Horns Rev (62 m; Tambke et al., 2005), Høvsøre (116 m; Gryning et al. 2007), Hamburg (250 m; Gryning et al., 2007), and Omø, Vindeby, and Rødsand (48-50 m; Lange et al., 2004; Motta et al., 2005). The length of the red lines denotes the relative height of the masts. The coastline is from the NOAA Shoreline Website (http://shoreline.noaa.gov/data/datasheets/wvs.html) and $30 \mathrm{~m}$ bathymetric contour (light line) is from ETOPO-1. (For interpretation of the references to color in this figure legend, the reader is referred to the web version of this article.)

Barth and Eecen, 2006 for overviews of monitoring programs in Germany, Denmark, and the Netherlands, respectively). The measured data provides information on wind profiles and atmospheric stability and can be used to directly evaluate the paradigm of wind profile shapes predicted from MO similarity theory. The offshore meteorological masts to conduct wind energy assessments are typically much higher than the instrument heights of ocean buoys or research vessels, and are less impacted by platform motion distortion effects that affect shipboard measurements in particular (Fairall et al., 1996; Peña et al., 2008). Based on analyses of the offshore mast data over the past decade, there is a growing body of evidence that indicates the MO theory may not be the best description of the wind profile in the first $100 \mathrm{~m}$ above the sea surface in coastal regions, and the height of applicability may be much lower (Barthelmie, 1999; Barthelmie et al., 2005; Sempreviva et al., 2008).

The meteorological problem centers on the presence of internal boundary layers (IBLs) in coastal regions that frequently occur when warm continental air flows over a cooler sea. A shallow cool air layer forms over the sea surface and deepens only gradually moving downstream according to vertical shear mixing criteria. Researchers have employed different terms to describe the phenomenon, which is most often identified with 'decoupled layers' near the bottom of the MABL (Lange et al., 2004) and air layers that are 'not in equilibrium' with the sea surface (Sempreviva et al., 2008). Along with low level jets from which they are distinguished (Bergström, 2001; Beran et al., 2005), IBLs give rise to smaller scale vertical and horizontal structure in coastal regions, and especially anomalous vertical wind shear. In northwestern Europe, the IBLs in offshore regions are prevalent in the springtime, and in the Baltic Sea - semi-enclosed by continental land masses - IBLs may be present during two-thirds of the year (Smedman et al., 1997). Although the issue of offshore IBLs has come to prominence in the two decades through the analysis of data sets from offshore meteorological masts (Barthelmie et al., 2005), they have been recognized in previous work dealing with radar propagation (Sheppard, 1946; Kerr, 1951), naval smoke screens (Woodcock and Wyman, 1947), and pollution dispersion studies (Schacher et al., 1982; Gryning, 1985; Hasse and Weber, 1985; Hsu, 1988). For offshore wind energy, the anomalous wind shear profiles (e.g., Riedel et al., 2005) that are associated with IBLs have potential economic consequences for estimating extractable wind energy where measurement masts do not extend to hub height (Barthelmie et al., 2005; Sempreviva et al., 2008) and also through increasing fatigue loads that may contribute to turbine breakdown and maintenance (Eliassen et al., 2012; Ernst and Seume, 2012). Early reviews of the Danish offshore wind monitoring program in the Baltic Sea, starting from the first offshore mast at Vindeby, have noted a problem with vertical wind profiles that are mostly linked with flows across nearby coastlines (Barthelmie, 1999; Barthelmie et al., 2005). Intensive research at the $50 \mathrm{~m}$ meteorological Rødsand mast in Denmark has characterized the anomalies in the measured vertical wind speed profiles particularly during stable conditions when the vertical wind shear is much steeper than expected from MO theory (Lange, 2004; Lange et al., 2004). The Rødsand site is surrounded by land areas with fetches of $10-100 \mathrm{~km}$ (depending on wind direction), and the anomalous wind profiles are associated with advection of warm air from the nearby land areas particularly during early spring when the land heats up more rapidly than the seawater (Lange et al., 2003). For wind farm operations, the situation demands a meteorological measurement mast at hub height as it is difficult to accurately predict wind speed across a decoupled atmospheric layer (Lange et al., 2003; Barthelmie et al., 2005).

The eastern North Sea near the coast of Denmark and Germany (Fig. 1) is expected to show less pronounced IBL effects where the prevailing westerly winds define long fetch conditions on the order of several hundred kilometers from the coast of Great Britain (Tambke et al., 2005). In a comparison of data from the Rødsand tower and the $100 \mathrm{~m}$ FINO1 platform in the southern German Bight, Lange (2004) highlighted differences in the wind speed profile measurements at the two sites, noting that FINO1 shows better agreement with MO theory than Rødsand under neutral and stable conditions. The result outwardly indicates that FINO1 may be unaffected by IBLs for winds from the prevalent direction from the west. Yet, even at the FINO1 site deviations were identified in the wind speed profile particularly unstable conditions, and the measured wind shear between $50 \mathrm{~m}$ and $30 \mathrm{~m}$ was lower than predicted from MO theory. Looking closer at the FINO1 data, Riedel et al. (2005) clarified that there are deviations of the measured wind speed profiles both at highly stable and highly unstable conditions. During stable conditions, the wind speed profile tends to show higher wind shear than MO theory, and during unstable conditions the wind speed shear is too low compared with MO theory. These observations led Riedel et al. (2005) to conclude that MO theory may not be appropriate for the FINO1 site. Instead, climatological wind speed profiles may be based directly on a statistical analysis of the FINO1 data, which was possible at this site because the tower extends up to turbine hub height. Other analyses of the FINO1 data have further characterized anomalous trends in the wind speed profile (Türk et al., 2008; Argyle and Watson, 2014), including a significant incidence of reversed profiles (Türk et al., 2008) where the measured wind speed at $33 \mathrm{~m}$ height is larger than at $100 \mathrm{~m}$. Reversed profiles are not possible within the framework of MO theory, and this suggests a more serious problem with the logarithmic wind profile concept. Case studies using FINO1 wind data as ancillary information to support wind speed retrievals from synthetic aperture radar images have also noted deviations from the MO expected profiles 
for the $10 \mathrm{~min}$ average data ( $\mathrm{Li}$ and Lehner, 2013), so that questions arise about the nature and prevalence of nonstandard wind profiles in the southern North Sea.

At other measurement locations in the North Sea, a similar picture is emerging of the high incidence of internal boundary layers, particularly during stable atmospheric conditions. At Horns Rev off the coast of Denmark, Tambke et al. $(2005,2006)$ reported anomalous trends in the uppermost $(62 \mathrm{~m})$ anemometer of a vertical wind instrument array. The trend was not present in an identical mast at the Laeso wind farm off the eastern Danish coast, so there was an indication of possible IBLs below $50 \mathrm{~m}$ height at the Horns Rev site. In a more detailed analysis of the wind profile data from Horns Rev, Peña et al. (2008) also noted deficiencies in the normal logarithmic wind profile description in stable atmospheric conditions, which could be rectified with the model of Gryning et al. (2007) that extends through the depth of the boundary layer. At the $116 \mathrm{~m}$ OWEZ mast off the Netherlands coast, anomalous vertical wind profiles have been noted during conditions of stable atmospheric stratification. These could not be described within the context of MO theory (Sathe et al., 2011; Brand et al., 2012), and there is an implication of coastal effects. Beran et al. (2005) pointed out the presence of boundary layer jets in radiosonde data from the Ekofisk oil platform in the middle of North Sea and suggested an evolution of the IBLs that were measured further upstream at the FINO1 platform closer to the German coast.
There is ambiguity in the height above the sea surface where the wind speed profile can be described with MO theory, particularly near coastlines. Over land, the surface layer and the logarithmic wind profile may extend to greater than $100 \mathrm{~m}$, as indicated by Gryning et al. (2007) for high onshore masts at Cabauw (Netherlands), Høvsøre (Denmark) and Hamburg (Germany). Land surfaces typically have large roughness lengths that create a mechanical mixing environment where surface effects may penetrate quite far into the atmospheric boundary layer to form a deep equilibrium layer. The marine atmospheric boundary layer is different, and the lower levels of turbulence (Emeis, 2013) mean that the layer in mixing equilibrium with the surface may be much lower (Barthelmie et al., 2005). Thus, for cases of stable stratification and low to moderate wind, the surface layer may only be on the order of 10-20 m deep (Barthelmie, 1999; Tambke et al., 2006; Emeis, 2013), and stable internal boundary layers may persist greater than $50 \mathrm{~km}$ from the coast (Garratt, 1990; Barthelmie, 1999).

IBLs and low level jets have been identified as important open questions in boundary layer meteorology with serious implications for offshore wind energy. Part of the issue is a lack of data and background research to define the occurrence, persistence and evolution of IBLs in different offshore areas. The goal of this report is therefore to present a survey of vertical characteristics in the offshore atmospheric boundary layer of the southern North Sea to

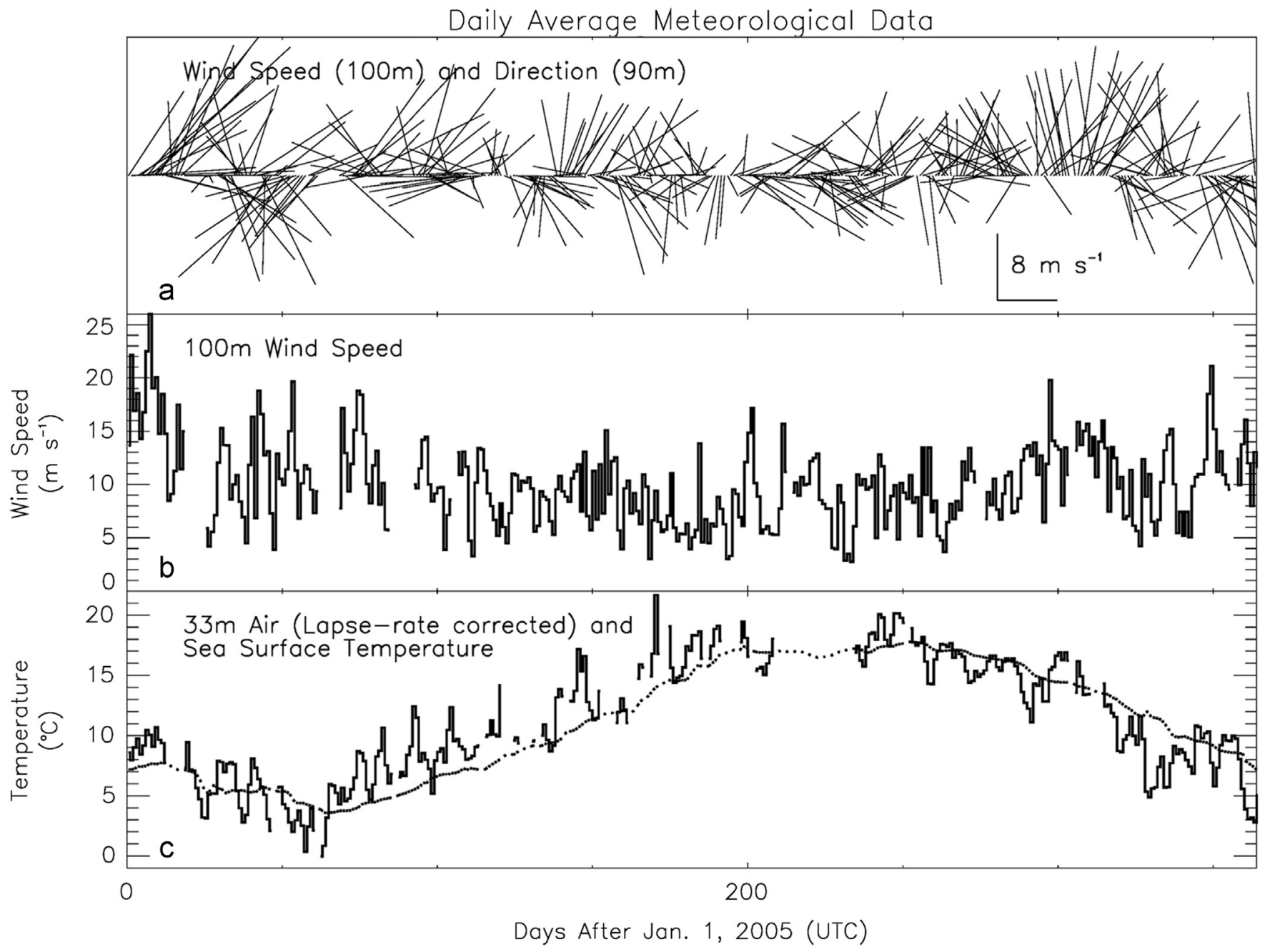

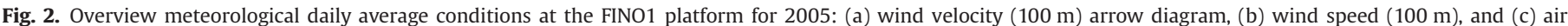
(heavy line) and near surface sea temperature (thin dotted line). 
reveal features of the vertical dynamics of the atmosphere over the sea.

\section{Theory}

A priori the vertical wind speed profile in the lower atmosphere is described according to a power law or a modified loglinear profile within the context of the MO theory (Petersen et al., 1998). The power law profile is given by

$\frac{U\left(z_{1}\right)}{U\left(z_{2}\right)}=\left(\frac{z_{1}}{z_{2}}\right)^{\alpha}$

where $U\left(z_{1}\right)$ and $U\left(z_{2}\right)$ are the wind speeds at heights of $z_{1}$ and $z_{2}$, and $\alpha$ is the power law exponent with a typical value of 0.2 for onshore applications and 0.14 for offshore applications (Türk et al., 2008; Ernst and Seume, 2012). The equation is used in engineering applications to make vertical extrapolations of wind speeds from single measurements typically at heights that are lower than the hub height of a wind turbine. Reviewing the parameterization, Petersen et al. (1998) state that the power law exponent varies with height, surface roughness, and stability, so that the equation may have limited use in understanding the underlying physical dynamics of the surface boundary layer. Because of this apparent weakness, the equation is sometimes not mentioned in reviews of boundary layer dynamics (Sempreviva et al., 2008; Peña et al., 2009). On the other hand, the equation is conceived as a simple and general data extrapolation scheme (Emeis, 2013), which

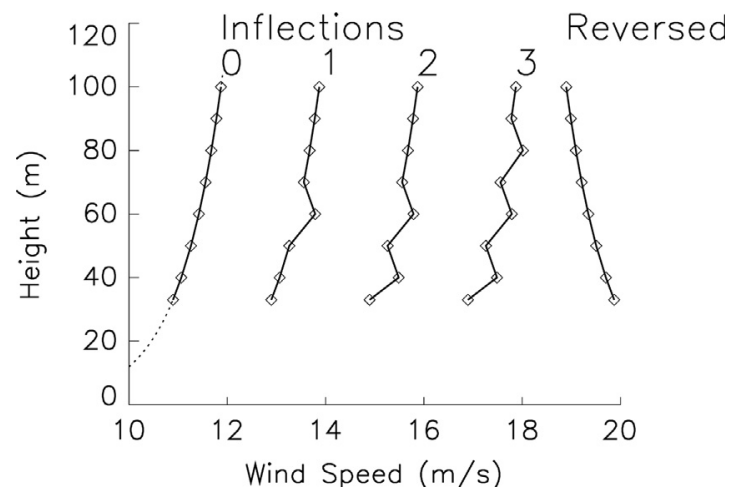

Fig. 4. Schematic diagram to illustrate the criteria for categorizing the measured vertical wind profiles according to the number of local maxima, (with an extra category for the reversed profiles). Case 0 is the expected profile, which is monotonically increasing through the lower boundary level. Cases 1,2 , and 3 have 1,2 , and 3 (respectively) local maxima. The local maxima can occur at any of the 6 internal points of the measurement profile. The reversed case denotes a profile that is decreasing monotonically upward through the lower boundary layer. The wind speed profiles shown in Fig. 3 can have complicated shapes and patterns, but they can all be assigned to the 5 cases on the basis of the 10 -min average wind speed measurement at the 8 discrete height intervals.

a

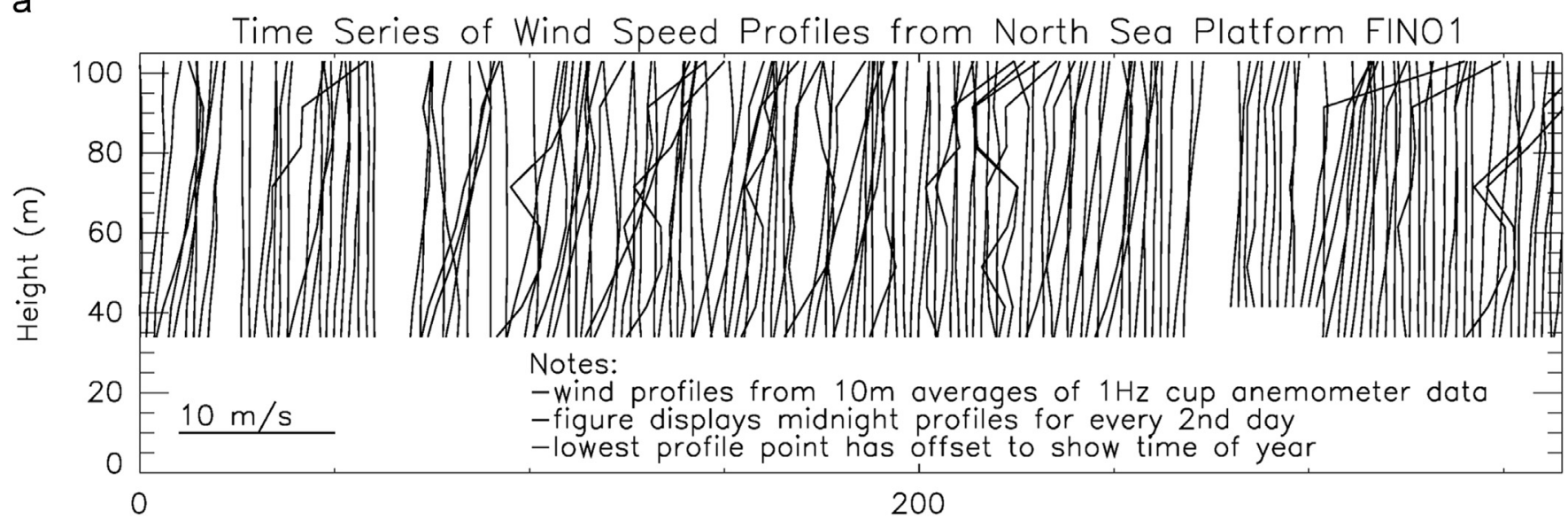

b

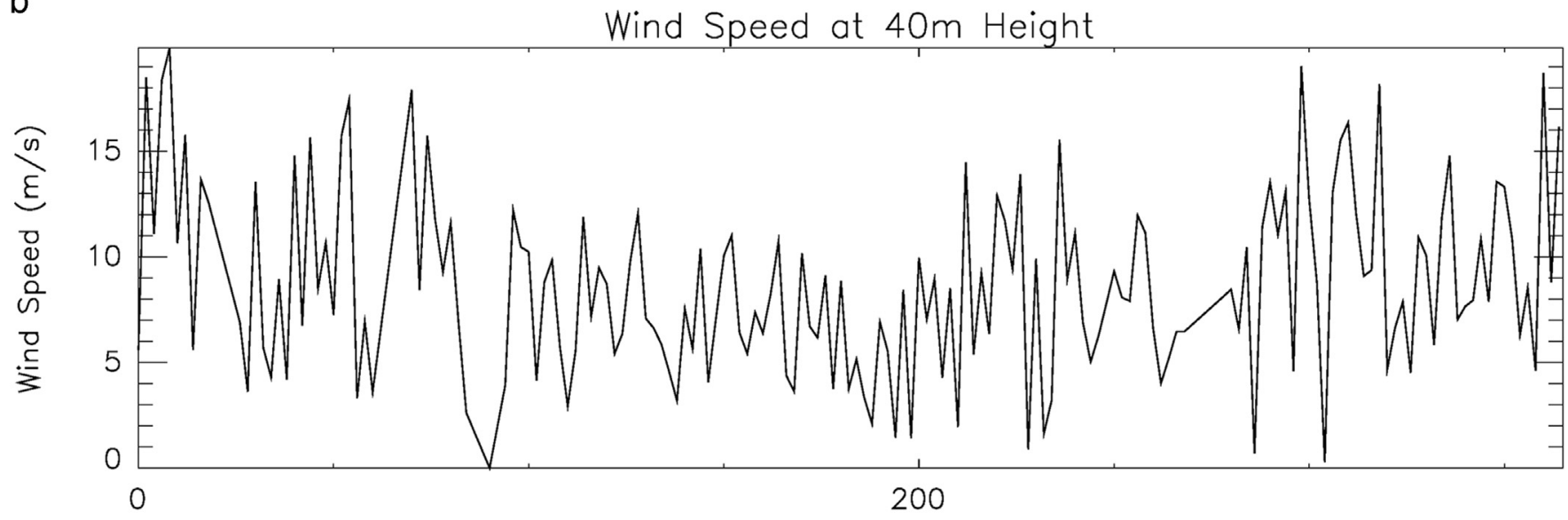

Days After Jan. 1, 2005

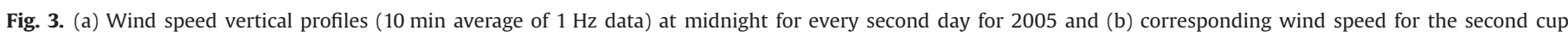

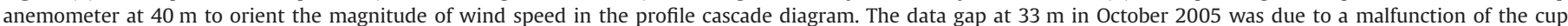
anemometer. 

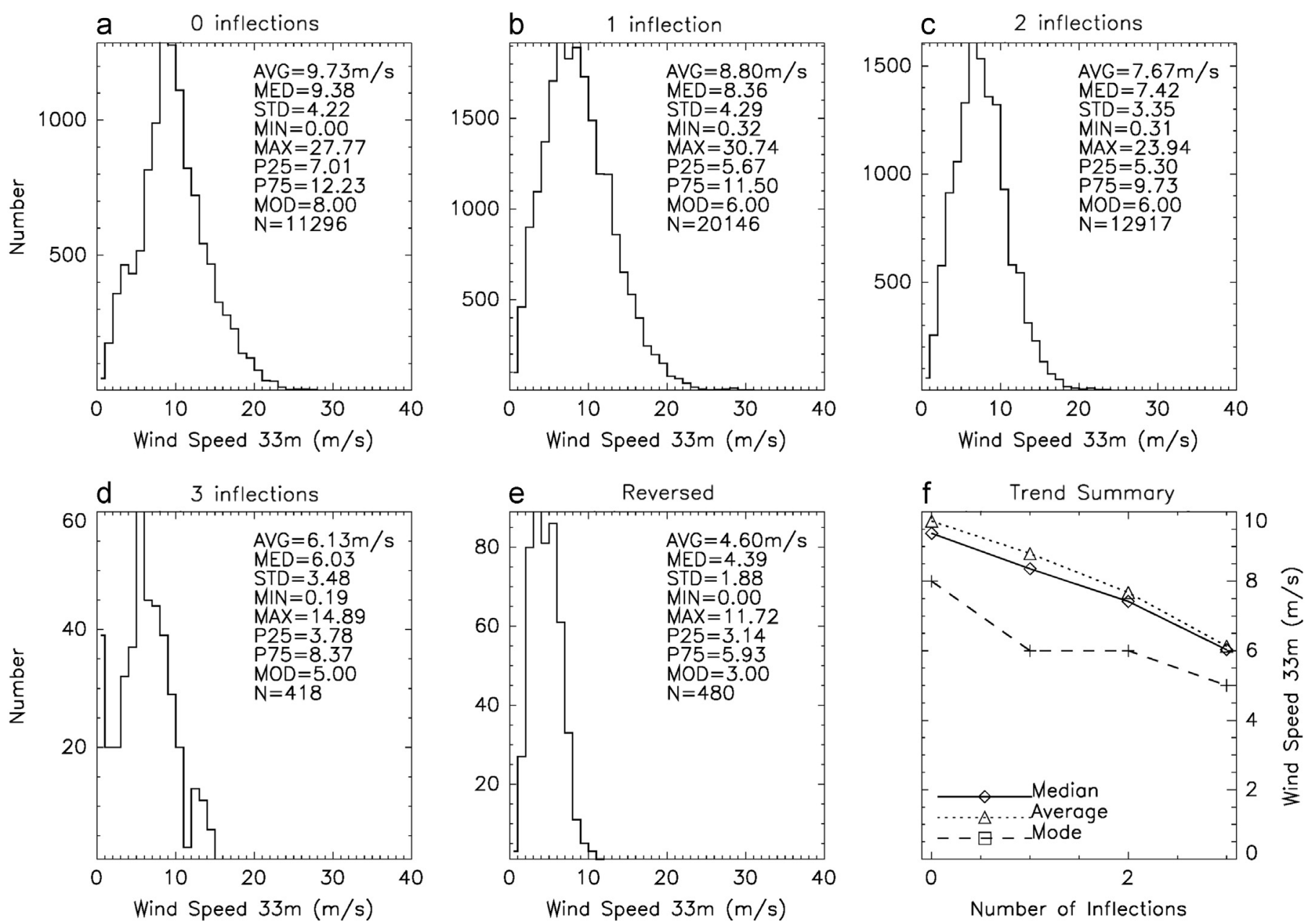

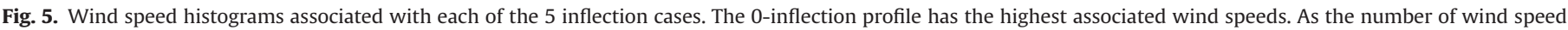

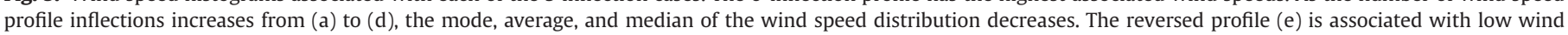
speeds. The trend summary (f) highlights that the number of profile inflections tends to increase as the wind speed decreases.

makes its use in turbine design safety schemes more desirable where physical principles underlying boundary layer dynamics are less certain. For the measured vertical wind profiles in the Baltic Sea (Lange et al., 2004) and North Sea (Tambke et al., 2005; Riedel et al., 2005; Emeis, 2013) that are impacted by IBLs, it may be better to use the power law profile where the theoretical basis of the boundary layer circulation is not clear (Emeis, 2013).

The modified log-linear wind speed profile is a development of the MO similarity theory that takes the form:

$U(z)=\frac{u_{*}}{\kappa}\left[\ln \left(\frac{z}{z_{0}}\right)-\psi\right]$

where $u_{*}$ is the friction velocity, $\kappa$ is the von Karman constant, $z_{0}$ is the roughness length, and $\psi$ is a stability dependent function, which is positive-valued for unstable conditions and negativevalued for stable conditions. The equation was developed from micrometeorological studies on land and modified to interpret flux measurements over the oceans (Fairall et al., 1996, 2003). Because neutral conditions are predominant in the atmospheric boundary layer over the open ocean, the stability function has been neglected in earlier offshore wind energy studies, and the vertical wind profile then assumes a simple logarithmic shape (Barthelmie, 1999). The advantage of the equation is that it incorporates simple elements of the physics of the surface layer and can be used to make predictions. For neutral conditions, a plot of the vertical wind speed profile versus the logarithm of the measurement
Table 1

Number of wind speed profiles from the FINO1 offshore mast categorized according to local maxima (inflections) and reversed characteristics. The data are based on 10 min averages from 2005

\begin{tabular}{lcc}
\hline Profile description & Number of profiles & Percentage of total \\
\hline 0-Inflection & 11,296 & 25.0 \\
1-Inflection & 20,146 & 44.5 \\
2-Inflection & 12,917 & 28.5 \\
3-Inflection & 418 & 0.9 \\
Reversed & 480 & 1.1 \\
\hline
\end{tabular}

height will typically produce estimates of friction velocity and the roughness length that are in accord with theory when averaged over extended time intervals (Wills, 1992; Peña et al., 2009). On the other hand, individual measured profiles often show large scatter, so that the physical behavior of the surface layer is only revealed in long-term average statistics extending to months or years for some studies. To some extent, part of the problem with the scatter is due to the fact that the MO equation is not applied according to the appropriate conditions stipulated for its use: (1) stationary time series, (2) averaged over time intervals of 10-60 min, (3) at measurement sites with long fetch (Petersen et al., 1998; Peña et al., 2009). When these criteria are applied strictly to reject data, more appropriate results may be obtained 
with the MO equation but with $<25 \%$ of the original data remaining (Lange et al., 2004; Sathe et al., 2011; Argyle and Watson, 2012). Where so many profiles deviate from the expected logarithmic wind profile, the MO model might not effectively represent the true physical situation, and a paradigm problem might be flagged (Argyle and Watson, 2012). Part of the issue might be that the surface layer over coastal regions is much shallower than over land, so heights above 10-20 m might often be in the Ekman layer where MO theory is not applicable (Barth and Eecen, 2006; Sathe et al., 2011; Emeis, 2013).

Because offshore wind energy developers must deal with $100 \%$ of the wind profiles in assessing extractable wind energy and turbine lifetimes, an important motivation for the present report is to examine the vertical wind profile more closely and understand the frequency and character of nonstandard profile shapes.

\section{Data and methods}

The FINO1 tower is located in the German Bight in the southern North Sea, approximately $40 \mathrm{~km}$ north of the island of Borkum (Fig. 1). It was set up in 2003 to establish a data set of the metocean conditions, structural loads, and environmental impacts of a meteorological mast in support of offshore wind energy development in Germany (Neumann et al., 2003; Argyriadis et al., 2006; Faber and Steck, 2006; Fischer, 2006; Rehfeldt et al., 2007). Compared with other offshore measurement masts, FINO1 has a large amount of instrumentation. The closely spaced vertical array of eight cup anemometers (Vector Instruments A100LM, 0.2 knot or $\sim 0.1 \mathrm{~m} / \mathrm{s}$ accuracy; Windspeed Ltd., 2003) from $33 \mathrm{~m}$ to $100 \mathrm{~m}$ provides a unique data set of high quality long-term wind speed records at approximately $10 \mathrm{~m}$ resolution (Türk and Emeis, 2010). Accurate wind direction measurements are available at $30 \mathrm{~m}$ and $90 \mathrm{~m}$. Air temperature temperatures were measured at 33, 40, 50, 70, and $90 \mathrm{~m}$, and Nolopp and Neumann (2006) give descriptions of the calibration procedure with a field intercomparison exercise that was performed twice in early 2004 and 2005/ 2006 (personal communication, F. Kinder, DEWI, December 12, 2013). Water temperature is measured by instruments mounted at $3,6,10,15,20$, and $25 \mathrm{~m}$ on a chain extending through the center of the supporting jacket lattice structure. The instrumentation is described at the BSH website: http://www.bsh.de/en/Marine_data/ Observations/MARNET_monitoring_network/FINO_1/index.jsp.

The data were recorded at a frequency of $1 \mathrm{~Hz}$ and archived at BSH as 10 min mean values. Data recovery rates were the highest in the first years of the mast operation, and the analysis in this report uses the 10 min data from 2005 to obtain a description that covers a full annual cycle.

Although the FINO1 data is regarded as a high quality dataset within the boundary layer meteorology community (Türk and Emeis, 2010), the information has features that must be considered in the interpretation. All instrumented meteorological measurement masts have flow distortion that affects the wind speed and direction measurements (e.g., Wills, 1982 for West Sole;
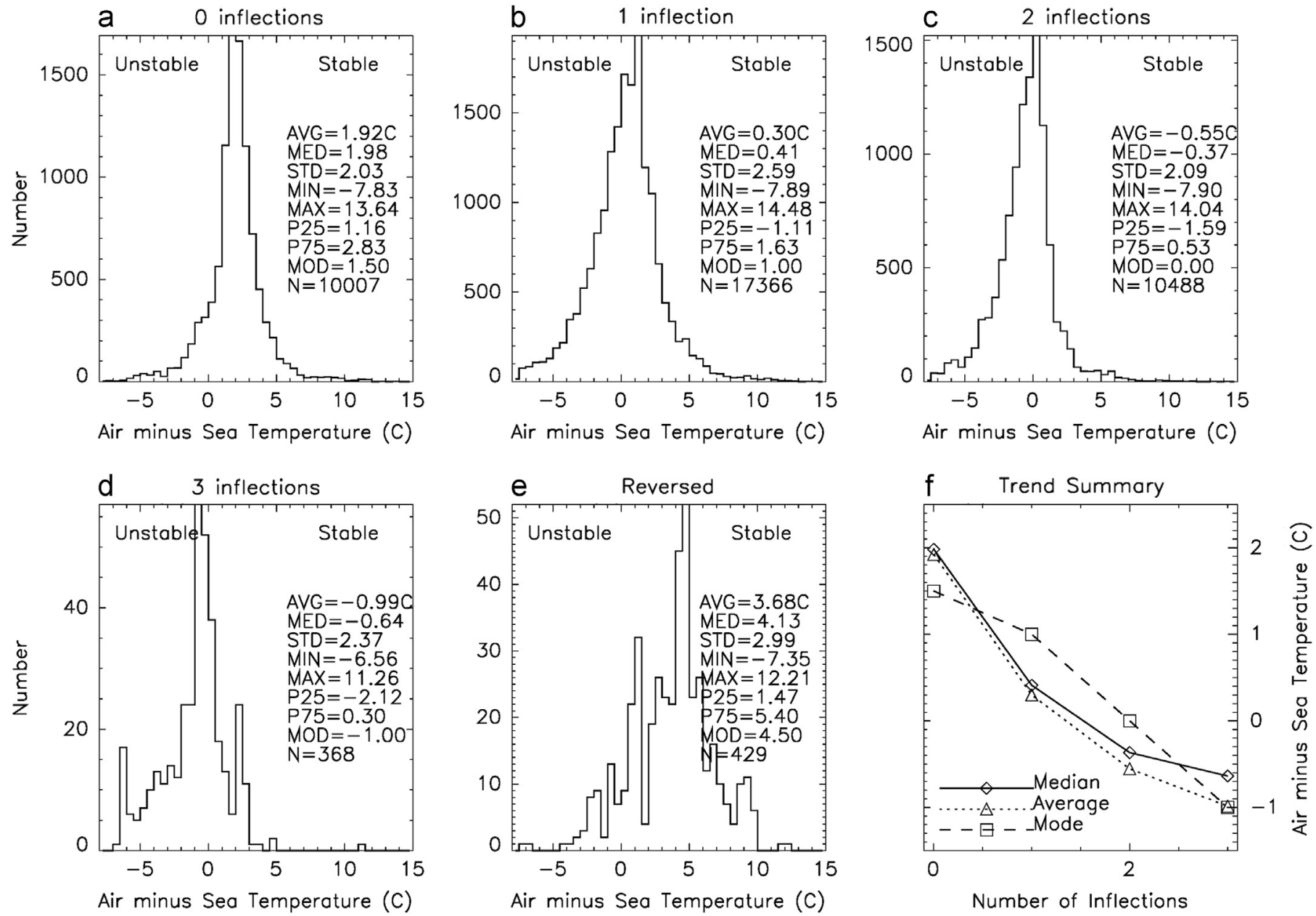

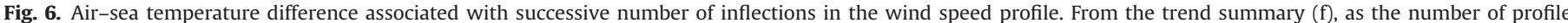
inflections increases, the mode, average, and median of air-sea temperature difference move from stable toward unstable conditions. 
Coelingh et al., 1992 for K13; Heggem, 1997 for Skipheia; Lange et al., 2004 for Rødsand; Barth and Eecen, 2006 for OWEZ). For FINO1, the cup anemometers are mounted on horizontal booms of 3.0$6.5 \mathrm{~m}$ length that face $135-143^{\circ}$ toward the southwest (personal communication, F. Kinder, DEWI, February 11, 2011). The cup anemometer at $100 \mathrm{~m}$ has a different mounting from the other cup anemometers and is placed at the top of mast within a fairly small 4-posted lightning cage. The side mounted anemometers show a mast attenuation effect when the wind is from the northwest, but comparison with the sonic anemometers on the northwest side of the mast indicates that there is also a smaller flow distortion effect for other wind directions (Lange, 2004; Westhellerweg et al., 2011). The cup anemometer at $100 \mathrm{~m}$ shows indications of a speed up effect as winds pass over the structure. Also the lightning cage causes wind speed reductions and speedups of up to $\sim 15 \%$ for wind directions close to the position of the supporting posts (Westhellerweg et al., 2011). Different strategies have been developed to address these flow-induced biases. Many studies use the full dataset without modification, and Bilstein and Emeis (2010) and Emeis (2013) note that including the impacted wind sectors only introduces a small bias in the final results for their assessments of average wind speeds. Other studies exclude the wind direction sector $280-350^{\circ}$, which is directly located in the mast shadow (Türk et al., 2008; Ernst and Seume, 2012). Within the DEWI group, which is responsible for data collection at FINO1, algorithms have been developed to account for the flow distortion effects of the mast (Westhellerweg et al., 2011). For the results in the present study, the entire analysis was conducted twice: once using all the data from 2005 and then once again excluding data when the wind was from $280-350^{\circ}$. Because the results in the graphs do not change significantly when the mast shadow sector is excluded, the study shows only the results from the analysis of the full dataset.

Aside from issues related to the structural distortion of the wind field, there were secondary issues associated with instrument breakdown. The most serious meteorological instrumentation malfunction was a cup anemometer at $33 \mathrm{~m}$ that resulted in a data gap of one month in October, 2005 before it was exchanged (personal communication, F. Kinder, DEWI, August 5, 2013). For the underwater temperature records, there were more data gaps of longer duration at different depths. However, the North Sea is well-mixed in this area throughout the year (Mann and Lazier, 2006; Fischer et al., 2010), and estimates of sea temperature near the surface could be made from at least one temperature record in
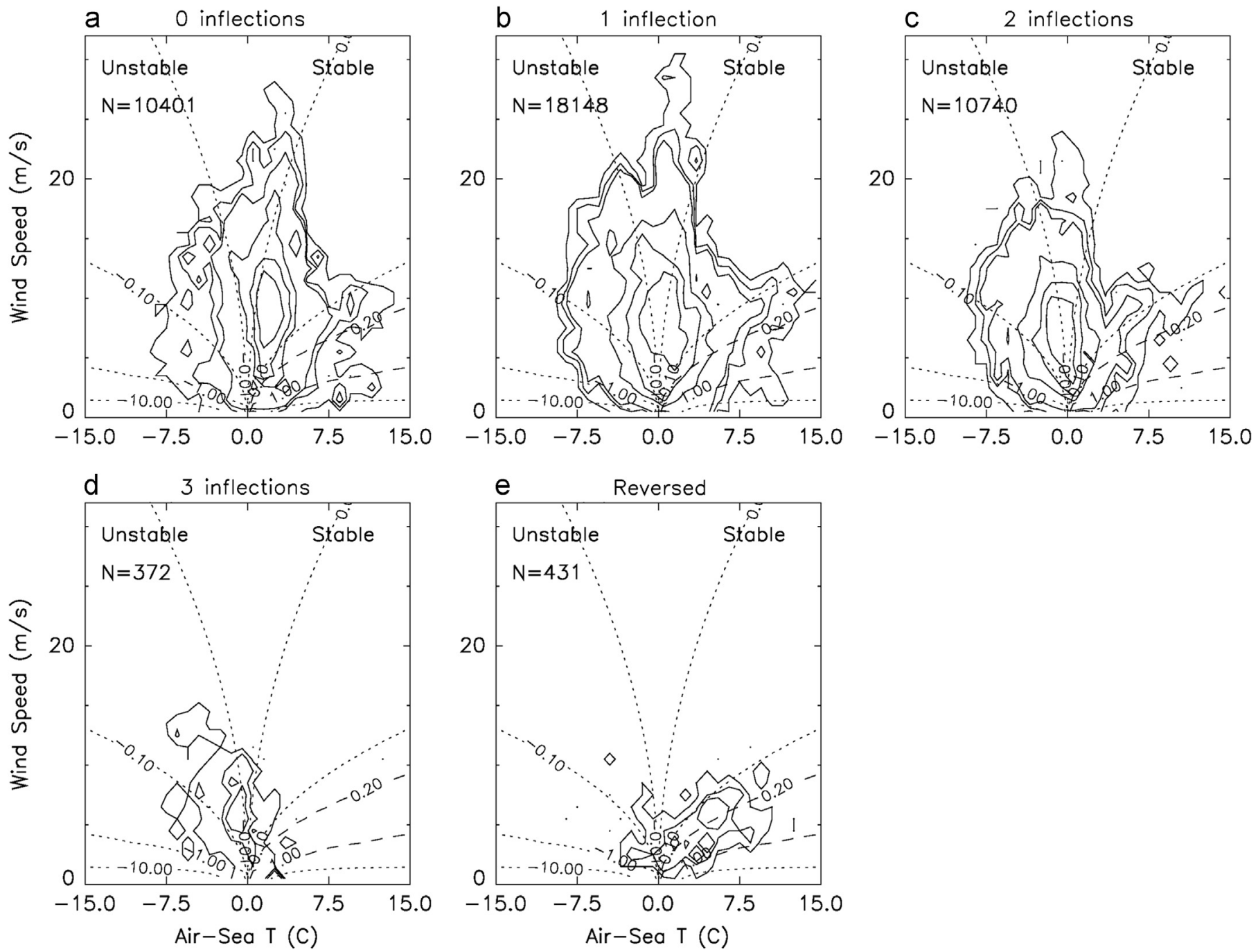

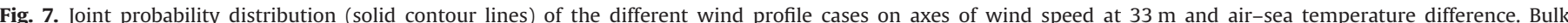

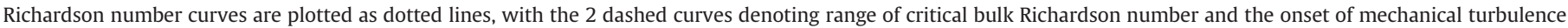

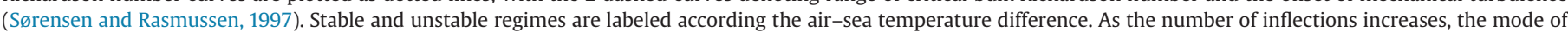

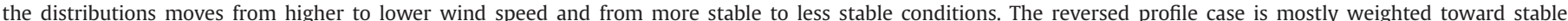
atmospheric regimes with low winds, and is located in a region of the diagram where the bulk Richardson number criteria indicates active mechanical mixing. 


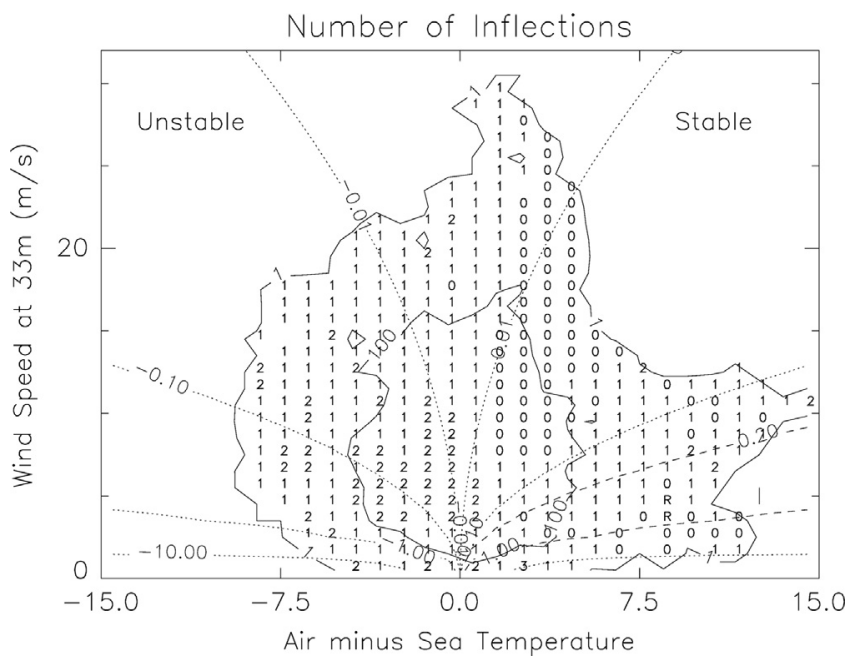

Fig. 8. Dominant case of number of inflections on axes of wind speed ( $33 \mathrm{~m}$ ) versus air-sea temperature difference. The joint probability distribution of the full data set (solid contour lines) is overplotted in solid lines. Bulk Richardson number curves are plotted as dotted lines, with the 2 dashed curves denoting range of critical bulk Richardson number and the onset of mechanical turbulence (Sørensen and Rasmussen, 1997). The 1-inflection case (denoted ' 1 ') is dominant in many parts of the panel, including the high wind speed regimes. However, the 0 -inflection wind profile case dominates in a sector of the slightly stable conditions for wind speed increasing from $8 \mathrm{~m} / \mathrm{s}$, in a regime that could indicate recently-completed mechanical mixing. The 2 -inflection case is most prevalent in a sector of low winds and unstable conditions. The reversed profile case (denoted ' $\mathrm{R}$ ') is dominant only in a limited area of high atmospheric stability and low winds. The 3-inflection case is dominated by other profile cases at most regimes of wind speed and air-sea temperature difference, and has only one occurrence on the diagram.

the water column. Overall, data availability from the FINO1 platform is high in 2005 in comparison with earlier offshore masts (Wills, 1992; Barthelmie, 1999).

Atmospheric stability for this analysis of FINO1 data is calculated as the difference in air temperature and near surface sea temperature. Other measures of atmospheric stability include vertical atmospheric temperature gradients, Monin-Obukhov length, and gradient or bulk Richardson number (Andersen and Løvseth, 1995; Blanc, 1983; Lange, 1994). While diagnostic quantities based on atmospheric gradients may better reflect the short-term dynamical situation of the atmosphere (Andersen and Løvseth, 1995), they require carefully intercalibrated instruments and consideration of potential problems associated with temporal drift and other effects (Blanc, 1983). By contrast, atmospheric stability based on air-sea temperature difference has proven to be the most robust diagnostic in cases where the temperature instrument calibration is not absolutely certain (Schacher et al., 1982; Blanc, 1983; Andersen and Løvseth, 1995), and this has been used here.

\section{Results}

An overview of the wind and atmospheric stability conditions at the site is given in Fig. 2 by the daily average values of wind speed, wind direction, air temperature, and sea temperature at the FINO1 site for 2005. The winds at the FINO1 are predominantly from the west southwest (Fig. 2a) and are higher in winter than in summer (Fig. 2b). Seasonal trends in air-sea temperature difference are shown in Fig. 2c. Air temperature is generally higher than sea surface temperature in the springtime and early summer, defining stable conditions in the lower atmosphere. From late summer to early winter, air temperatures are generally lower than the sea temperature, and this defines unstable atmospheric conditions.
A time series of vertical profiles of $10 \mathrm{~min}$ average wind speed is shown as a cascade diagram in Fig. 3. The wind speeds are from the vertical array of cup anemometers that extend from 33 to $100 \mathrm{~m}$ with $\sim 10 \mathrm{~m}$ resolution. From the total number of profiles available from 2005, a subset has been selected to illustrate the issue of the nonstandard profiles at FINO1 location, and Fig. 3 shows profiles at midnight (UTC) for every second day. The graph highlights that there are many profiles for which the wind speed increases with height, and this monotonic trend is the a priori expectation. However, there are a number of vertical wind speed profiles that deviate substantially from this scheme. Some of these show exaggerated shear, but there are also a number of profiles with local maxima and minima within eight instruments that define the vertical array. These profiles indicate that there are differences between the measurements and the theoretical profiles from MO theory. However, it is unclear from Fig. 3 how the vertical wind speed profiles are linked with other parameters that define the physical conditions at the site: wind speed and direction, air-sea temperature difference, time of day, etc. Also, it is unclear how long the anomalous profiles last and how they transform with the 'normal' profiles expected from theory.

To investigate these questions, the time series of vertical wind profiles defined by the measurements from the eight cup anemometers was separated into a small number of the categories based on anomalies from the monotonic increasing profile. Profiles that show wind speeds that are monotonically increasing with height are assigned to the ' 0 -inflection' case, irrespective of if the measured profile has the shape of the modified logarithmic profile given by Eq. (2). Profiles with a single inflection, where the $10 \mathrm{~min}$ average measurement at a single height is greater than those immediately above and below are assigned to the '1-inflection' case, irrespective of the height of occurrence. Previous studies have defined the height of the equilibrium surface layer by discontinuities or 'kinks' in the vertical wind profile, and these are a more direct indication of the active dynamical mixing height compared with the thermodynamic properties, air temperature or humidity (Garratt, 1990). Because there are eight cup anemometers, multiple wind profile 'kinks' may occur within the vertical array. Where there are two heights where the wind speed measurements are higher than the measurements immediately above and below, the profile is assigned to the '2-inflection' case. Likewise, where there are three heights that show local wind speed maxima, the profile is assigned to the '3-inflection' case. The defining criteria for the different cases are shown in the schematic diagram in Fig. 4, although the actual wind profiles do not necessarily have a logarithmic shape and the inflections may occur at any height. A last case ('Reversed') is defined by a profile that decreases monotonically with height. This is not possible within the context of MO theory (Eq. (2)) but can be parameterized within the framework of the power law profile (Eq. (1)). All of the profiles in Fig. 3 can be unambiguously partitioned among the five categories. The wind speed profile data were not filtered according to a standard deviation criterion over the $10 \mathrm{~min}$ assessment interval, as MO theory holds that Eq. (2) is correct for the assumed averaging period (Petersen et al., 1998). Also, the data were not preselected for wind profiles with kinks greater than a minimum measurement threshold, and the Vector Instruments A100LM anemometer is quoted with a high measurement accuracy of $\sim 0.1$ $\mathrm{m} / \mathrm{s}$ (Windspeed Ltd., 2003). Part of the motivation to avoid data filtering was to avoid introducing artefacts, a potentially serious problem that was highlighted by Argyle and Watson (2012).

The most important result from this analysis is the relative number of the different wind profile cases, shown in Table 1. While the a priori expectation is that the 0 -inflection situation would dominate, most of the wind profiles at FINO1 show a 


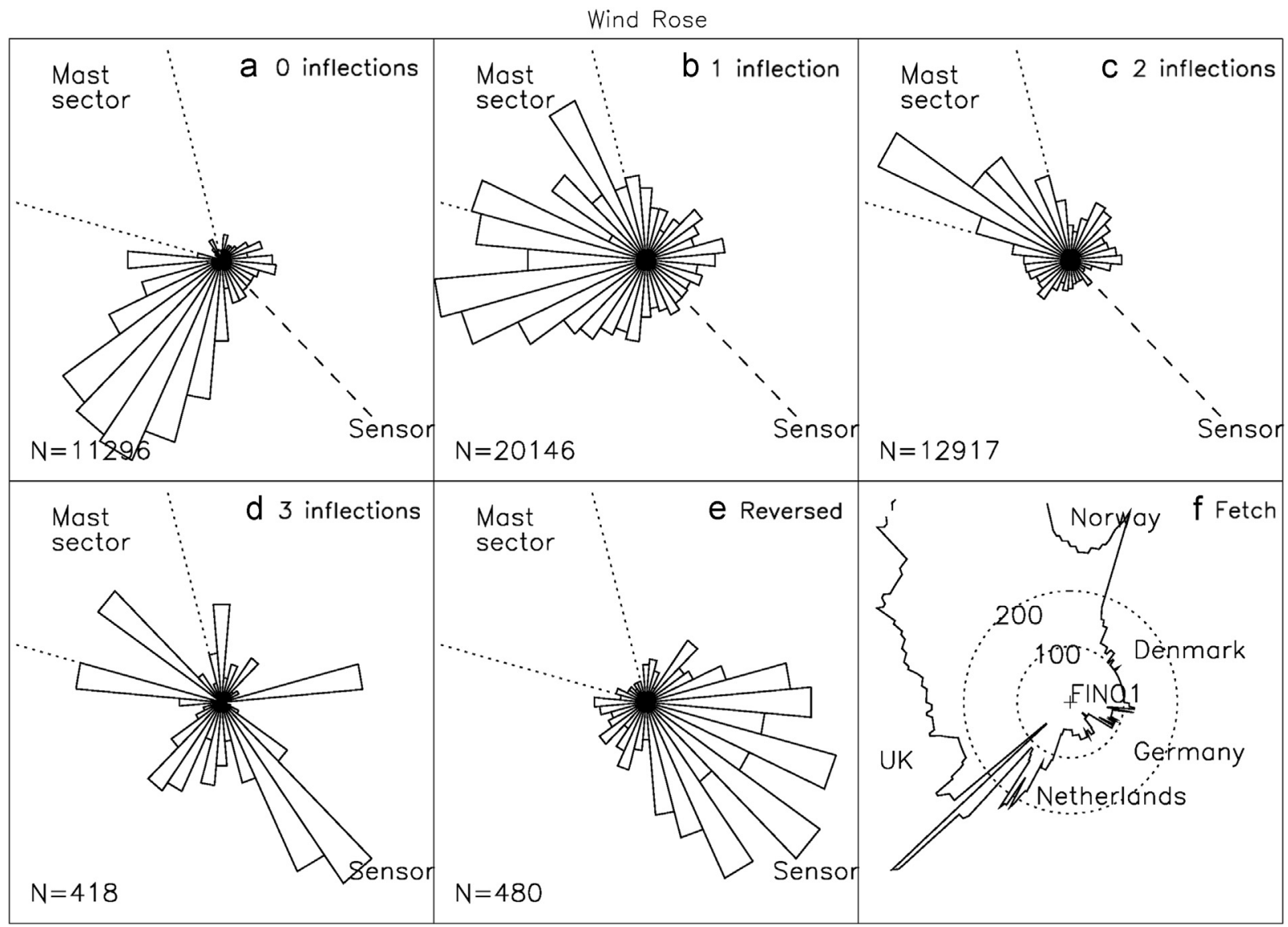

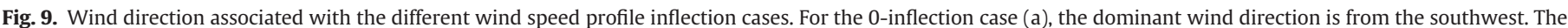

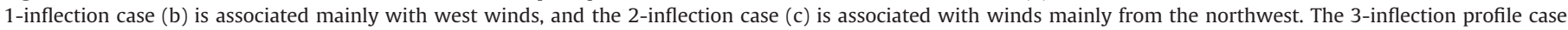

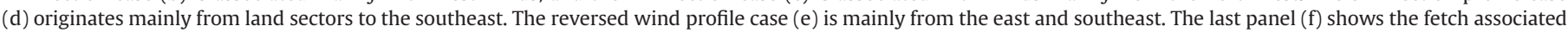
with the different directions around FINO1with the longest fetch toward the Nordic Seas to the northeast.

1-inflection situation. Of the 1-inflection profiles, 34\% of the cases have kinks in the uppermost layer at $90 \mathrm{~m}$, decreasing almost linearly to $\sim 4 \%$ in the lowest layer at $40 \mathrm{~m}$. The 1-inflection case is almost twice as frequent as the 2-inflection case. The expected 0 -inflection case is the third most prevalent form. The reversed profile and 3-inflection profile have frequencies that are more than an order of magnitude smaller than the first three dominant forms. The relative order of incidence of the different cases does not change if data in the mast sector is excluded, and the conclusions below do not change whether or not data from the mast sector are excluded. The remainder of the study therefore deals with the full dataset irrespective of the wind direction.

\subsection{Number of Inflections by wind speed and stability}

Dynamical and thermodynamic constraints in the atmospheric boundary layer are often considered in the context of wind speed and air-sea temperature difference. Wind speed gives an indication of the mechanical mixing tendency of the boundary layer, and the air-sea temperature difference is an indication of thermally driven mixing by heating at the bottom of the air column. In the first survey of the information, it was important to assess if the different wind profile cases were linked with these fundamental parameters. Fig. 5 shows how the different wind profile cases are linked with the $33 \mathrm{~m}$ wind speed. The diagram indicates that the number of inflections in the wind profile does not correlate directly to measured wind speed. On the other hand, there is a trend in the median of wind speed distributions and the number of inflections in the vertical profiles. The 0 -inflection profile has the highest median wind speed, and this decreases with increasing numbers of wind profile inflections through to the 3-inflection profile. The reversed wind profile shape has the lowest median $33 \mathrm{~m}$ wind speed, and does not occur at high wind speeds that are much above $10 \mathrm{~m} / \mathrm{s}$.

The air-sea temperature difference that is associated with the different wind profile cases is shown as a series of histograms in Fig. 6. Each wind profile case is associated with a range of values for air-sea temperature difference. However, the statistics of the histogram distributions vary with the number of inflections in the vertical wind speed profiles. The 0 -inflection profile is associated mostly with stable atmospheric conditions with the air temperature warmer than the underlying ocean surface. The median of the histogram distributions decreases as number of profile inflections increases, so the 2- and 3-inflection cases are linked most often with unstable atmospheric stability, where the sea surface temperature is warmer than the overlying air. The reversed wind speed profile is associated with the highest conditions of atmospheric stability, and it seldom occurs during unstable conditions.

The link between the number of wind profile inflections and wind speed and atmospheric stability is shown as a joint probability distribution in Fig. 7. The plots for the first three predominant cases (with 0,1 , or 2 inflections) outwardly show similar features. However, a comparison reveals how the mode in the distributions shifts from higher to lower wind speeds and from positive to negative values of air-sea temperature difference as the number of profile inflections increases. The very different conditions of atmospheric stability that are associated with the 3-inflection case (mostly unstable conditions) and the reversed profile case (mostly stable conditions) are highlighted. Dotted lines are overplotted on the figure to denote the approximate bulk Richardson number that is determined mostly by the wind speed 

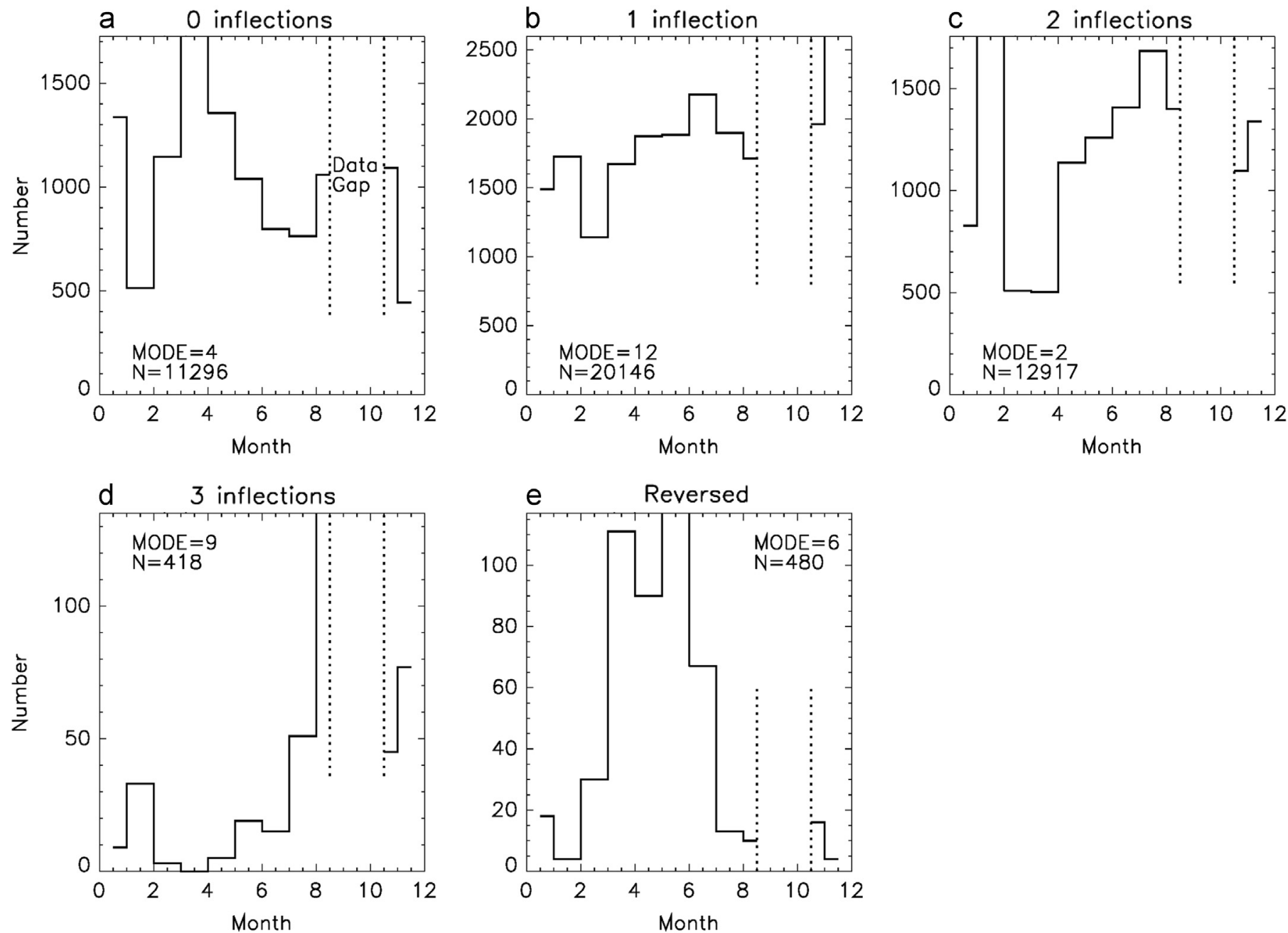

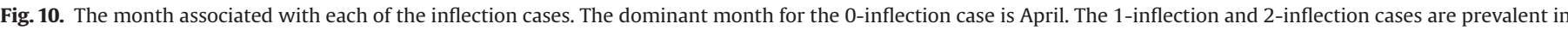

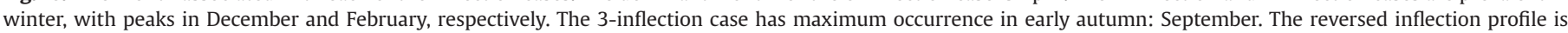

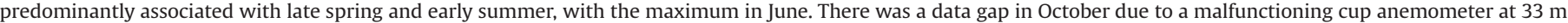
height.

and air-sea temperature difference. Dashed lines give the range of critical bulk Richardson numbers assessed from the literature (Sørensen and Rasmussen, 1997).

The overlap in the different panels in Fig. 7 indicates that a given wind speed and air-sea temperature difference cannot be used to assess the wind profile inflection state unambiguously. On the other hand, there are regimes of wind speed and air-sea temperature difference where certain wind profile inflection cases tend to dominate, and these tend to cluster together on axes of wind speed versus air-sea temperature difference (Fig. 8). Profiles with a single wind profile inflection are dominant in many regimes of wind speed and atmospheric stability (both stable and unstable), and also at the highest wind speeds. Profiles with 2 inflections in the wind profile form a contiguous cluster at low winds and unstable conditions. By contrast, vertical wind profiles with 0 -inflections form a contiguous cluster in the sector that is characterized by stable atmospheric conditions and moderate to high wind speeds above $\sim 8 \mathrm{~m} / \mathrm{s}$. This is the sector that is just above the critical bulk Richardson number (Sørensen and Rasmussen, 1997), and suggests an atmospheric state that has just achieved a stable state through mechanical mixing. The reversed profiles form a small cluster of dominance at low speeds and high atmospheric stability in a dynamical regime that is normally associated with active mechanical mixing. Profiles with 3 inflections have just a single occurrence in the diagram in a low wind speed regime.

\subsection{Number of inflections by wind direction, month, and time of day}

Aside from direct conditions of wind speed and atmospheric stability, other factors that may affect the number of wind profile inflections are wind direction, month, and time of day. Fig. 9 shows how the number of wind profile inflections varies with wind direction, and it also shows the fetch associated with each wind direction (Fig. 9f). The dominant 1-inflection case is linked with wind speeds mostly from the west and northwest with fetches exceeding $200 \mathrm{~km}$. The 0 -inflection case is associated with wind directions from the southwest, which is aligned approximately with the coast of the Netherlands and Belgium and is also the predominant wind direction. The 2-inflection case is linked mainly with the northwest sector. This is the sector of the longest fetch toward the Nordic Seas. The reversed profile cases are associated mainly with flows from the continental land sectors in the southeast and east, and it is associated with the shortest fetches. The case with 3-inflection profiles is associated mainly with wind directions from the southeast.

Many of the wind profile cases are associated with particular seasons (Fig. 10). The 0 -inflection case is mainly linked with springtime conditions with the highest incidence in April. The 1-inflection case has the highest incidence in December. The 2-inflection case is dominant at two different times of year in February and August. The reversed case mainly occurs in the late 

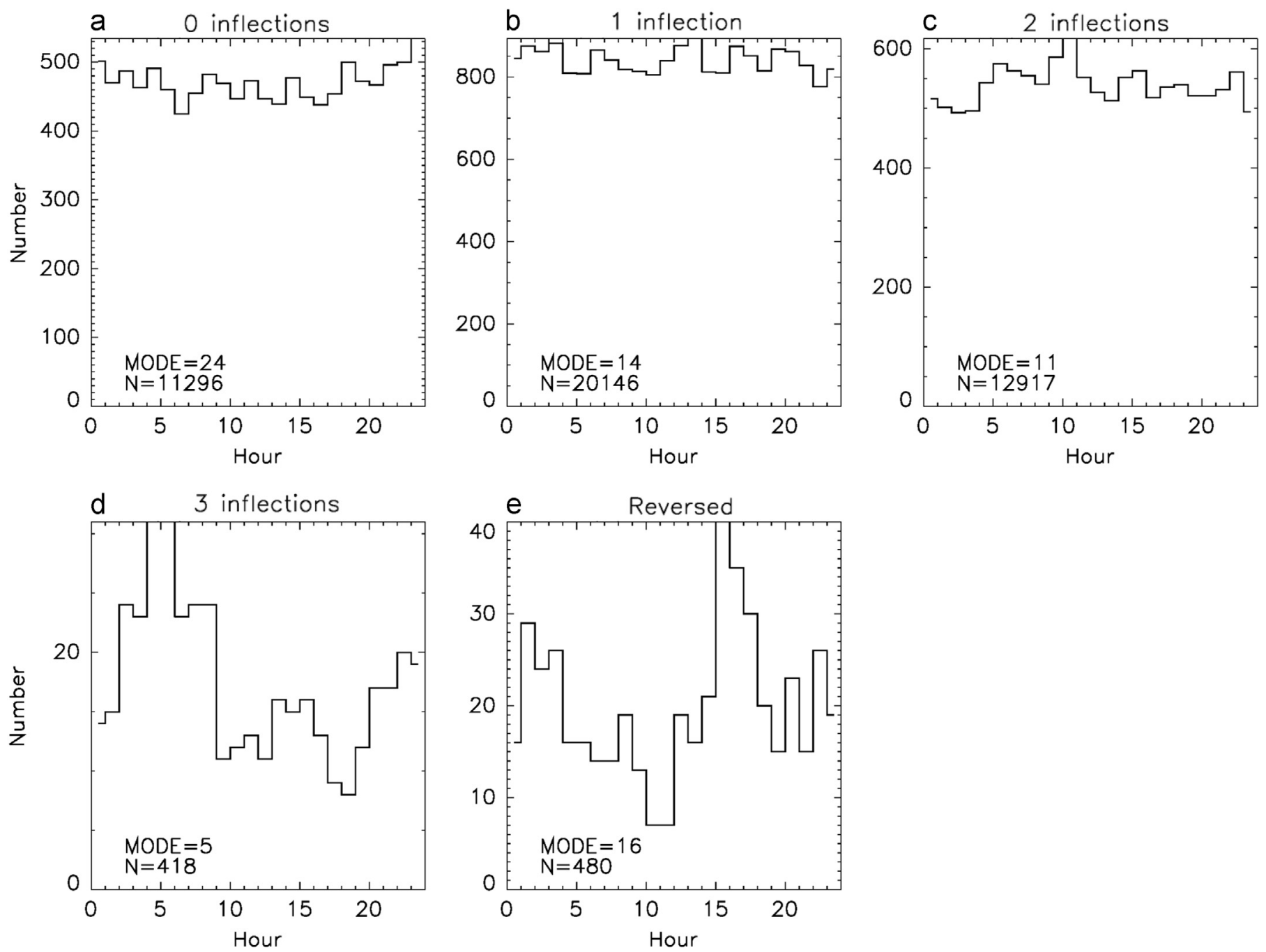

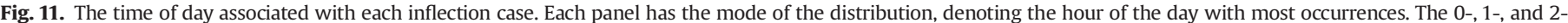

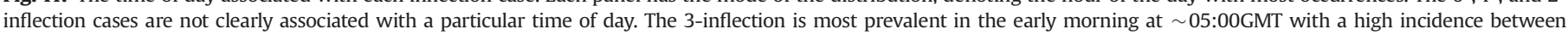
midnight and dawn. The reversed profile case is most prevalent in late afternoon.

spring and early summer in April, May, and June. The 3-inflection case has its highest occurrence in September, and may be linked with the onset of unstable atmospheric conditions in the late summer.

The 0-, 1-, and 2-inflection wind profile cases are not linked with a particular time of day (Fig. 11). The results are consistent with previous findings from other meteorological masts in the North Sea. Based on a statistical analysis of stability data from the OWEZ and Horns Rev platforms in the North Sea, Sathe et al. (2011) noted that there was not a strong link with time of day at these locations far offshore. Similar results were found by Argyle and Watson (2012) for masts at Shell Flats and Scroby Sands, off the west and east coasts of the UK, respectively. On the other hand, Motta et al. (2005) did find a significant diurnal variation of stability classes for three meteorological masts in eastern Denmark: Vindeby, Rødsand, and Omø. While technically situated in an offshore environment, these masts are surrounded by near-lying land areas so that the diurnal variation in stability likely reflects solar heating of land surfaces. For FINO1, the 3-inflection and reversed wind profiles also exhibit diurnal variations. The 3-inflection case shows a high incidence in the early morning between midnight and dawn. There is a high prevalence for reversed profile cases in the late afternoon. Along with the wind direction information (Fig. 9), this suggests that the diurnal variation of the reversed profiles may be linked with transport from land areas experiencing strong afternoon heating in early summer.

\subsection{Duration of the wind speed profile}

Except for the 0 -inflection case, the existence of multiple local wind speed maxima indicates mixing states that do not conform with the paradigm of MO stability theory. Based on the link with wind speed and atmospheric stability conditions, a conceptual model may be formulated of near-surface layers that are in equilibrium mixing contact with the sea surface, and upper layers that retain thermodynamic characteristics from greater distances, perhaps retaining the features of nearby land areas. The mixing processes that regulate the interchange of atmospheric inflection states appear to have an episodic character. Questions arise about the time scales of duration of the different inflection states and if distinguishing diagnostics may be formulated from the dataset.

The duration of the different inflection states is shown in Fig. 12. The histogram distributions for all the inflection states show an approximate linear decreasing trend when plotted on $\log -\log$ axis. The mode of the distributions in each case is the 

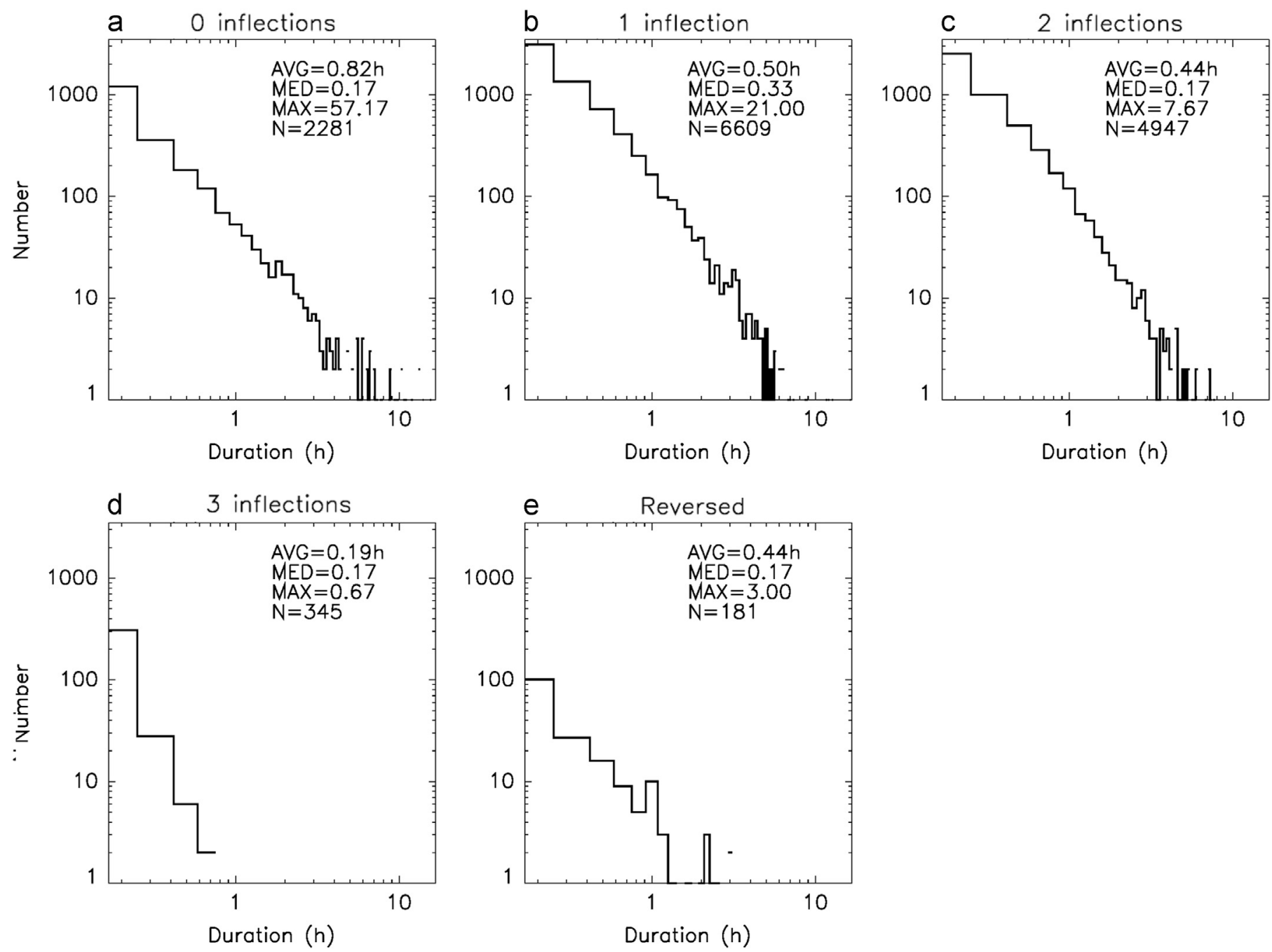

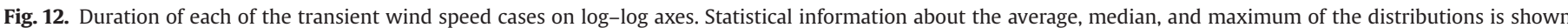

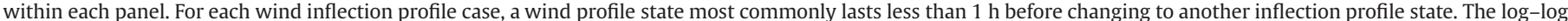

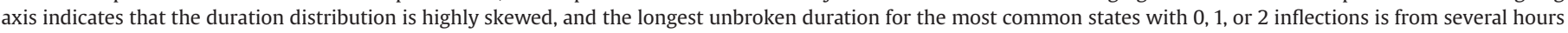
to over two days.

shortest time step of the original time series (10 min). The lifetime of a given inflection state is very short with an average of less than an hour. The histograms also indicate that there are very infrequent occurrences where an inflection state can last for longer intervals - hours or days - before switching to another inflection state. There is one extreme case of a 0 -inflection state lasting for over two days before switching to another inflection state (Fig. 12a). A closer analysis of how the different inflection states interchange reveals that most conversions take place through the 1-inflection state. There is a rapid switching among the dominant 0 -, 1-, and 2-inflection cases, with rarer flips into and out of the much rarer 3-inflection and reversed profiles. Although most conversions take place through the 1-inflection state, the data set shows that direct conversions among all the inflection states are possible. This indicates, for example, that the unusual reversed profile case is not necessarily preceded by a unique inflection state as a precursor to a change in atmospheric dynamics.

\section{Conclusion}

The results highlight the presence of nonstandard wind profiles at the FINO1 mast in the North Sea that do not conform to MO theory. In most cases, the vertical wind speed profiles have inflections at intermediate heights, which give a possible indication of decoupling of the atmospheric layers in the first $100 \mathrm{~m}$ over the sea surface. In some cases, the wind speed profiles show a reversed trend with the highest measured wind speeds nearest the surface. Both features indicate a breakdown of the standard MO profile shape description. To investigate the incidence and background of these profiles, the wind speed measurements from the 8 cup anemometers along the southeast side of the FINO1 measurement mast were separated into 5 categories based on the number of local maxima in the measured wind speed profile. From MO theory, the a priori expectation was that there would be no inflections, and the wind profile should increase monotonically upward from the sea surface. However, the most common measured profiles showed 1 or 2 inflections, and the expected 0 -inflection case appeared in a minority of cases.

An analysis was conducted to characterize the geophysical background of the wind profiles. For the wind profiles with 0,1 , and 2 inflections, there was significant overlap in the measured wind speeds and air-sea temperature differences. On the other hand, closer examination of the statistics revealed that the 0 -inflection case was associated with the highest statistical wind speeds and also the most stable atmospheric conditions. As the number of wind profile inflections increased from 0 to 3 , the median wind speed decreased, and the air-sea temperature 
difference progressed from stable to unstable conditions. At least for the 0 inflection case, the result was expected; MO theory is a description of a surface-linked equilibrium mixing regime that is most likely to occur with mechanical mixing associated with high winds. For the other inflection cases, the patterns are to some degree linked with wind speed and air-sea temperature differences through bulk Richardson number instability. Mechanical mixing regimes can be identified. Analysis of the duration of the different inflection cases revealed that they are short-lived features, lasting less than an hour before transformation a different inflection state.

Further profiling of the inflection cases reveals that they are associated with particular larger scale geophysical settings. The 0 -inflection case is associated mainly with the dominant flow from the southwest along the coast. The 1- and 2-inflection cases are associated with winds from the west and northwest. The reversed profile is associated mostly with the continental land sectors to east and southeast. There is a strong link between wind direction and the seasonal variation of atmospheric stability. The 0 -inflection case, which is associated with stable conditions, occurs mainly from early spring to early summer, and the multiple inflection cases mainly occur from late summer to early winter. The reversed wind profile is dominant in late spring and early summer. The most prevalent wind inflection cases (with 0,1 , and 2 inflections) do not show a diurnal variation of incidence, similar to previous findings from Horns Rev, OWEZ, Shell Flats, and Scroby Sands (Sathe et al., 2011; Argyle and Watson, 2012).

A growing body of results from a number of offshore meteorological masts indicates limitations in the use of MO theory to predict wind speed more than a few tens of meters above the sea surface. This was unexpected given previous scientific research results based mainly on measurements from oceanographic research vessels in the open ocean. The problem appears to be mainly the presence of IBLs in coastal regions that may extend tens or hundreds of kilometers offshore. The high incidence of IBLs had been documented for the Baltic Sea, but had not been expected in the southern part of the North Sea where fetches are much longer. Measurements from the FINO1 mast indicate that the height of the surface layer may be lower than mast height for a significant fraction of time so that MO theory may not automatically be the best description of the vertical wind profile (Emeis, 2013). For the 1-inflection case, the kinks are most prevalent in the height range of $80-100 \mathrm{~m}$ at approximately the hub height of modern offshore wind turbines. This may represent a challenge for designers seeking to develop a wind turbine generator to optimize power production subject to possible constraints of fatigue damage. Because of the limited $100 \mathrm{~m}$ height of the mast, it is unclear if the relative incidence of kinks increases higher in the boundary layer, and radiosonde and LIDAR techniques may offer dynamical insights in this region (Beran et al., 2005). The number offshore measurement masts is the North Sea area is not large and the performance of the mesoscale models to simulate IBLs is also limited (Bergstrom, 2001). From previous investigations in other parts of the world, it is known that IBLs start off shallow at the coastline and grow in depth with increases distances offshore (Mulhearn, 1981; Hsu, 1983, 1989), but it is unclear how the results from these earlier studies apply to a semi-enclosed basin like the North Sea. To obtain a picture of IBLs on larger regional scales, future research efforts should include synthesis projects to incorporate information from other masts across the North Sea basin as well as numerical weather prediction models (Vincent and Hahmann, 2011).

\section{Acknowledgments}

This work has been partially funded by the Norwegian Centre for Offshore Wind Energy (NORCOWE) under Grant 193821/S60 from the Research Council of Norway (RCN). NORCOWE is a consortium with partners from industry and science, hosted by Christian Michelsen Research. The main data source for this analysis is research project FINO (research platforms in the North Sea and Baltic Seas), which is funded by BMU, the Germany Federal Ministry for the Environment, Nature Conservation and Nuclear Safety (project no. 0325321).

\section{References}

Andersen, O.J., Løvseth, J., 1995. Gale force maritime wind. The Frøya data base. Part 1: sites and instrumentation. Review of the data base. J. Wind Eng. Ind. Aerodyn. 57, 97-109.

Argyle, P., Watson, S., 2012. A study of the surface layer atmospheric stability at two UK offshore sites. In: European Wind Energy Association (EWEA) Conference Proceedings, pp. 110-113.

Argyle, P., Watson, S.J., 2014. Assessing the dependence of surface layer stability on measurement height at offshore locations. J. Wind Eng. Ind. Aerodyn. 131, $88-99$.

Argyriadis, K., Fischer, G., Frohbose, P., 2006. Research Platform FINO1 - Some Measurement Results, EWEC 2006, Athens. 〈http://proceedings.ewea.org/ ewec2006/allfiles2/450_Ewec2006Fullpaper.pdf).

Arya, S.P., 2001. Introduction to Micrometeorology, 2nd edition Academic Press, San Diego.

Barth, S., Eecen, P.J., 2006. Description of the relation of wind, wave, and current characteristics at the offshore wind farm Egmond aan Zee (OWEZ) location in 2006. ECN Report, ECN-E-07-104, OWEZ_R_122_wave_2006.

Barthelmie, R.J., 1999. Monitoring offshore wind and turbulence characteristics in Denmark. In: Proceedings of the 21st British Wind Energy Association (BWEA) Conference. Cambridge, UK, September 1-3.

Barthelmie, R., Hansen, O.F., Enevoldsen, K., Højstrup, J., Frandsen, S., Pryor, S., Larsen, S., Motta, M., Sanderhoff, P., 2005. Ten years of meteorological measurements for offshore wind farms. Trans. ASME 127, 170-176.

Beran, J., Calveri, L., Lange, B., von Bremen, L., 2005. Offshore wind modelling and forecast. WRF/MM5 User's Workshop, June 6, 2005.

Bergström, H., 2001. Boundary-layer modelling for wind climate estimates. Wind Eng. 25, 289-299.

Bilgili, M., Yasar, A., Simsek, E., 2011. Offshore wind power development in Europe and its comparison with onshore counterpart. Renew. Sustain. Energy Rev. 15, 905-915.

Bilstein, M., Emeis, S., 2010. The annual variation of vertical profiles of Weibull parameters and their applicability for wind energy potential estimation. DEWI Mag. 36, 42-46.

Blanc, T.V., 1983. A practical approach to flux measurements of long duration in the marine atmospheric surface layer. J. Clim. Appl. Meteorol. 22, 1093-1110.

Brand, A.J., Wagenaar, J.W., Eecen, P.J., Holtslag, M.C., 2012. Database of measurements on the offshore wind farm Egmond aan Zee. EWEA, Copenhagen.

Breton, S.-P., Moe, G., 2009. Status, plans and technologies for offshore wind turbines in Europe and North America. Renew. Energy 34, 646-654.

Coelingh, J.P., van Wijk, A.J.M., Cleijne, J.W., Pleune, R., 1992. Description of the North Sea wind climate for wind energy applications. J. Wind Eng. Ind. Aerodyn. 39, 221-232.

Eliassen, L., Jakobsen, J., Obhrai, C., 2012. The effect of atmospheric stability on the fatigue life of offshore wind turbines. In: Proceedings of the Twenty-second (2012) International Offshore and Polar Engineering Conference, Rhodes, Greece, June 1-22, 2012. The International Society of Offshore and Polar Engineers, pp. 330-336.

Emeis, S., 2013. Offshore Winds, Wind Energy Meteorology (Chapter 5). SpringerVerlag, Berlin, pp. 95-133.

Ernst, B., Seume, J.R., 2012. Investigation of site-specific wind field parameters and their effect on loads of offshore wind turbines. Energies 5, 3835-3855.

Faber, T., Steck, M., 2006. 〈http://www.gl-group.com/pdf/WEA_zu_Wasser_und_zu_ Lande_Fab_MSte.pdf $>$ (e-document time stamp May 3, 2006).

Fairall, C.W., Bradley, E.F., Rogers, D.P., Edson, J.B., Young, G.S., 1996. Bulk parameterization of air-sea fluxes for Tropical Ocean-Global Atmosphere CoupledOcean Atmosphere Response Experiment. J. Geophys. Res. 101, 3747-3764.

Fairall, C.W., Bradley, E.F., Hare, J.E., Grachev, A.A., Edson, J.B., 2003. Bulk parameterization of air-sea fluxes: update and verification for the COARE algorithm. J. Clim. 16, 571-591.

Fischer, G., 2006. 15. Installation and operation of the research platform FINO1 in the North Sea. In: Köller, J., Köppel, J., Peters, W. (Eds.), Offshore Wind Energy. Springer-Verlag, Berlin, pp. 237-253.

Fischer, J., Herklotz, K., Senet, C., Outzen, O., Hahn, R., 2010. Oceanographic observations at FINO1 and the 'alpha ventus' offshore wind farm. In: Proceedings of the German Wind Energy Conference.

Garratt, J.R., 1990. The internal boundary layer - a review. Bound.-Layer Meteorol. $50,171-203$

Gryning, S.E., 1985. The Oresund Experiment - a Nordic mesoscale dispersion experiment over a land-water-land area. Bull. Am. Meteorol. Soc. 66, 1403-1407. 
Gryning, S.E., Batchvarova, E., Brummer, B., Jorgensen, H., Larsen, S., 2007. On the extension of the wind profile over homogeneous terrain beyond the surface boundary layer. Bound.-Layer Meteorol. 124, 251-268.

Hasse, L., Weber, H., 1985. On the conversion of Pasquill categories for use over sea. Bound.-Layer Meteorol. 31, 177-185.

Hsu, S.A., 1983. On the growth of a thermally modified boundary layer by advection of warm air over a cooler sea. J. Geophys. Res. 88, 771-774.

Hsu, S.A., 1988. Coastal Meteorology. Academic Press, San Diego.

Hsu, S.A., 1989. A verification of an analystical formula for estimating the height of the stable internal boundary layer. Bound.-Layer Meteorol. 48, 197-201.

Heggem, T., 1997. Measurements of Coastal Wind and Temperature. Sensor Evaluation, Data Quality, and Wind Structure (Ph.D. thesis). NTNU, Trondheim.

Kerr, D.E., 1951. Propagation of Short Radio Waves. McGraw-Hill Book Company, New York.

Lange, B., Larsen, S.E., Højstrup, J., Barthelmie, R., 2003. The wind speed profile at offshore wind farm sites. In: Proceedings of the OWEMES 2003 Conference, April 10-12, 2003. Naples, Italy.

Lange, B., 2004. Comparison of wind conditions of offshore wind farm sites in the Baltic and North Sea. In: Proceedings of the German Wind Energy Conference DEWEK 2004. Wilhelmshaven, Germany.

Lange, B., Larsen, S., Højstrup, J., Barthelmie, R., 2004. The influence of thermal effects on the wind speed profile of the coastal marine boundary layer. Bound.Layer Meteorol. 112, 587-617.

Li, X., Lehner, S., 2013. Observation of TerraSAR-X for studies on offshore wind turbine wake in near and far fields. IEEE J. Sel. Top. Appl. Earth Observ. Remote Sens. 6, 1757-1768.

Mann, K.H., Lazier, J.R.N., 2006. Dynamics of Marine Ecosystems. BiologicalPhysical Interactions in the Oceans. Blackwell Publishing, Malden, Massachusetts.

Motta, M., Barthelmie, R.J., Vølund, P., 2005. The influence of non-logarithmic wind speed profiles on potential power output at Danish offshore sites. Wind Energy 8, 219-236.

Mulhearn, P.J., 1981. On the formation of a stably stratified internal boundary layer by advection of warm air over a cooler sea. Bound.-Layer Meteorol. 21, 247-254.

Neumann, T., Nolopp, K., Strack, M., Mellinghoff, H., Soker, H., Mittelstaedt, E., Gerasch, W.J., Fischer, G., 2003. Erection of German offshore measuring platform in the North Sea. DEWI Mag. 23, 32-46.

Neumann, T., Nolopp, K., Herklotz, K., 2004. First operating experience with the FINO1 research platform in the North Sea. DEWI Mag. 24, 27-34.

Nolopp, K., Neumann, T., 2006. Temperature measurement on the FINO1 platform. DEWI Mag. 28, 54-59.

Nunalee, C., Basu, S., 2012. Mesoscale modelling of low-level jets over the North Sea. In: Peinke, J., et al., Wind Energy: Proceedings of the Euromech Colloquium.

Peña, A., Gryning, S.-E., Hasager, C.B., 2008. Measurements and modelling of the wind speed profile in the marine atmospheric boundary layer. Bound.-Layer Meteorol. 129, 479-495.

Peña, A., Hasager, C.B., Gryning, S.E., Courtney, M., Antonio, I., Mikkelsen, T., 2009. Offshore wind profiling using light detection and ranging measurements. Wind Energy 12, 105-124.

Petersen, E.L., Mortensen, N.G., Landberg, L., Højstrup, J., Frank, H.P., 1998. Wind power meteorology. Part 1: climate and turbulence. Wind Energy 1, 2-22.
Rehfeldt, K., Paschedag, U., Bömer, J., 2007. Offshore wind power development in Germany. Bundesministerium für Umwelt, Naturschutz und Reaktorsicherheit (BMU) and Stiftung Offshore Windenergie, January, 2007.

Riedel, V., Durante, F., Neumann, T., Strack, M., 2005. The first year of measurements on the FINO1 platform in the North Sea - evaluation and analysis of the wind profile and assessment of the statistical long-term mean value. DEWI Mag. 26, 37-48.

Sathe, A., Gryning, S.E., Peña, A., 2011. Comparison of the atmospheric stability and wind profiles at two wind farm sites over a long marine fetch in the North Sea. Wind Energy 14, 767-780.

Schacher, G.E., Fairall, C.W., Zanetti, P., 1982. Comparison of stability classification methods for parameterizing coastal over water dispersion. In: Proceedings of the First Conference Meteorology and Air Sea Interaction of the Coastal Zone. The Hague, pp. 77-82.

Sempreviva, A.M., Barthelmie, R.J., Pryor, S.C., 2008. Review of methodologies for offshore wind resource assessment in European Seas. Surv. Geophys. 29, 471-497.

Sheppard, P.A., 1946. The structure and refractive index of the lower atmosphere, in meteorological factors in radio-wave propagation. Report of a conference held on 8 April 1946 at the Royal Institution, London. The Physical Society, London, pp. 37-79.

Smedman, A.-S., Bergstrom, H., Grisogono, B., 1997. Evaluation of stable internal boundary layers over a cold sea. J. Geophys. Res. 102, 1091-1099.

Sørensen, J.H., Rasmussen, A., 1997. Method for calculation of atmospheric boundary-layer height used in ETEX dispersion modeling. In: Proceedings of the Sixth Topical Meeting on Emergency Preparedness and Response, San Francisco, California, April 22-25, pp. 503-506.

Sun, X., Huang, D., Wu, G., 2012. The current use of offshore wind energy technology development. Energy 41, 298-312.

Tambke, J., Lange, M., Focken, U., 2005. Forecasting offshore wind speeds above the North Sea. Wind Energy 8, 3-16.

Tambke, J., Claveri, L., Bye, J.A.T., Poppinga, C., Lange, B., von Bremen, L., Durante, F. Wolff, J.O., 2006. Offshore meteorology for multi-mega-watt turbines. In: EWEC 2006 Scientific Proceedings.

Türk, M., Grigtusch, K., Emeis, S., 2008. The wind profile above the sea investigations basing on four years of FINO1 data. DEWI Mag. 33, 12-16.

Türk, M., Emeis, S., 2010. The dependence of offshore turbulence intensity on wind speed. J. Wind Eng. Ind. Aerodyn. 98, 466-471.

Vincent, C.L., Hahmann, A.N., 2011. Hour-scale wind fluctuations over the North Sea. EWEA Annual Event, Brussels, Belgium, March 14-17, 2011.

Westhellerweg, A., Riedel, V., Neumann, T., 2011. Comparison of LIDAR- and UAMbased offshore mast effect corrections. EWEA 2011 Brussels.

Wills, J.A.B., 1982. Report on the West Sole Wind Structure Project 1982. National Maritime Institute, Feltham, Middlesex TW14 OLQ, UK, OT-R-8240, NMI R 145 April, 1982.

Wills, J.A.B., 1992. Offshore wind structure measurements at the West Sole gas platform. J. Wind Eng. Ind. Aerodyn. 41-44, 2465-2473.

Windspeed Ltd., 2003. A100LK and A100LM Low Power Pulse Output Anemometers Specification Sheet, Vector Instruments, 115 Marsh Road, Rhyll, Denbighshire, LL18 2AB, UK.

Woodcock, A.H., Wyman, J., 1947. Convective motion in air over the sea. Ann. N. Y. Acad. Sci. 68, 749-777. 